\title{
Editorial
}

\section{Urethral Catheters, Condom Catheters, and Nosocomial Urinary Tract Infections}

\author{
John W. Warren, MD
}

There is an emerging body of data indicating that a symptomatic urinary tract infection (UTI) results not just from bacteria being in urine but from bacteria in some way perturbing urinary epithelium. Fortunately, the normal urinary tract has a number of defense mechanisms that prevent or minimize those bacteria-epithelial cell interactions that are disadvantageous to the host. ${ }^{1}$ Although most organisms causing UTI have colonized the periurethral area previously, the urethra itself is an effective obstacle to bladder inoculation. If organisms traverse the urethra and enter the bladder, the next urination will clear $99.9 \%$ of these bacteria, a process enhanced by TammHorsfall protein and oligosaccharides that are suspended in urine and that bind bacteria. Even after the most effective micturition, however, a film of urine remains adjacent to the bladder mucosa. Fortunately, glycosaminoglycan overlays bladder epithelium and inhibits bacterial adherence to epithelial cells. Moreover, there appears to be a poorly understood bacteriocidal mechanism closely associated with bladder mucosa; this is effective even in the absence of polymorphonuclear leukocytes or antibodies. An acute inflammatory response is initiated, at least in part, by cytokines released from infected epithelial cells. The last protective effort of an epithelial cell is a sacrificial one: exfoliation of the cell allows attached organisms to be voided from the host. Polymorphonuclear leukocytes arrive within hours and ingest infecting bacteria and either may kill them or carry them into the urine, where the phagocytes are voided with their captured prey. Antibodies and cell-mediated immunity are part of a slower response, but perhaps useful in the later stages of the acute infection.
The use of a urethral catheter can thwart some of these defense mechanisms. Insertion of the catheter may push or drag urethral organisms into the bladder, and the catheter's lumen and external surfaces continue to act as bacterial conduits through the urethra. The catheter enhances uropathogen colonization of the urethra, particularly in women. The inner and outer surfaces of the catheter become niches for adherent bacteria, which form a biofilm that covers and secures them against urine flow and polymorphonuclear leukocytes. As a foreign body, the catheter may blunt adequate antibacterial polymorphonuclear leukocyte function. Catheter drainage often is imperfect, and larger volumes of urine remain in the bladder. Finally, the presence of the catheter may mechanically damage the adjacent glycosaminoglycan layer and epithelium.

Nevertheless, each year millions of urethral catheters are placed in patients in acute-care hospitals, in long-term-care units, and for home healthcare use. The incidence of bacteriuria is $3 \%$ to $10 \%$ per day of indwelling urethral catheterization. Consequently, the duration of catheterization is the most important risk factor for the development of bacteriuria. The majority of catheterized patients are bacteriuric by the end of 30 days, a convenient dividing line between short-term (generally hospital) and long-term (generally nursing home or home) catheterization. Although usually asymptomatic, catheter-associated bacteriuria may be complicated acutely by fever, acute pyelonephritis, bacteremia, and death; and, over prolonged catheterization, by urinary tract stones, local peri-urinary infections, chronic pyelonephritis and interstitial nephritis, renal failure, and (over years) bladder cancer.

From the Division of Infectious Diseases, University of Maryland School of Medicine, Baltimore, Maryland. Address reprint requests to John W. Warren, MD, Professor of Medicine, Head, Division of Infectious Diseases, University of Maryland School of Medicine, 10 S Pine St, Baltimore, MD 21201-1192.

95-ED-222. Warren JW. Urethral catheters, condom catheters, and nosocomial urinary tract infections. Infect Control Hosp Epidemiol 1996;17:212-214. 
Prevention of these ill effects of catheterization has been addressed in three stages. The first has been to prevent bacteriuria once the catheter is in place; the closed catheter system was a magnificent step forward, but few modifications have improved upon it. The second, once bacteriuria has occurred, has been to prevent its complications; however, with present technology, our ability to do so is limited. The third, and most direct, method to prevent catheterassociated bacteriuria and its complications is to prevent catheterization itself. This understanding has prompted increasing attention to the use of alternatives including patient training, biofeedback, medications, surgery, special clothes and bedclothes, and devices that are options to the urethral catheter.

Based on these considerations, in 1982, the Danish National Centre for Hospital Hygiene issued recommendations for management of indwelling catheters and encouraged the use of alternative urine collection devices. In an earlier report, ${ }^{2}$ Zimakoff et al provided data consistent with a subsequent decrease in the prevalence of indwelling catheters on Danish medical wards. In this issue, the same authors used definitions of UTI developed by the US Centers for Disease Control and Prevention and offer evidence that, while the prevalence of overall nosocomial UTIs has remained stable, the proportion associated with indwelling catheters has dropped from $66 \%$ in 1978 to $30 \%$ in 1991 . Based on their logistic regression analysis, they imply that UTIs associated with condom catheters make up some of the balance. Indeed, they point out that odds ratios of association with UTI are higher with condom catheters than with indwelling catheters. Their interpretation of these data is that condom catheters "have emerged as significant risk factors for urinary tract infection." 3

Setting aside issues such as selection of hospitals and days of investigation, comparability of hospitals in the before and after studies, and the relative dearth of ICU patients, the reader still may have several questions that are left unanswered by this report. The first involves the diagnosis of UTI. Obtaining an adequate urine specimen for culture requires different procedures for indwelling urethral and condom catheters. The use of sterile techniques to aspirate urine from the distal indwelling urethral catheter is an effective method of preventing contamination from skin and bowel organisms. Among condom wearers, as the authors point out, colonization of the skin of the distal penis and urethra with numerous organisms, including bowel flora, is common. Special attention is needed for adequate urine collection for purposes of culture ${ }^{4,5}$; otherwise, routine methods result in high rates of false-positive condom-associated
UTIs. ${ }^{4}$ Methods of urine collection for culture are not described well in the present report. The second question has to do with the concept of duration of device-associated risk. 6 The longer a device is in place, the more likely an associated infection will develop. If, in the reported survey, condom catheters had been in use, on average, for longer periods of time than urethral catheters, then condom catheters would be associated with a relatively higher UTI prevalence. Unfortunately, we are provided no data of duration of condom versus indwelling catheter use in these populations. Finally, a related question has to do not with duration of device use but duration of associated UTIs. Because prevalence is a function of incidence and duration of the infection, differences in duration of UTI (however diagnosed) in indwelling and condom catheter users would affect a comparison of the two methods of bladder management. This is one reason why incidence rates are better measures of risks of infection, ${ }^{7}$ although prevalence rates, as in this study, are easier to obtain.

Like many prevalence studies, this survey is useful for generating hypotheses. Given the reported odds ratios, one hypothesis might be that the risk (ie, incidence) of UTI with condom catheters is higher than with indwelling urethral catheters. This seems unlikely, as the condom is external to the urinary tract and thus doesn't provide the ingress, intra-host foreign body, and damage to bladder epithelium that the indwelling urethral catheter does. Furthermore, the best evidence to date that examines this hypothesis consists of parallel studies in one nursing home in which prospective incidences of symptomatic UTI were measured in men with chronic indwelling and condom catheters. 8,9 Ouslander et al found that the incidence of symptomatic UTIs among men with indwelling catheters was two and one-half times that among men with condom catheters. Their study, however, was not a prospective, randomized, controlled trial, which would be the ideal method to test this hypothesis. Indeed, such properly designed trials comparing urethral catheterization to any of its options, not only condom catheters but also intermittent catheterization, suprapubic catheterization, and diapers, would be welcomed.

\section{REFERENCES}

1. Warren JW. Host-parasite interactions and host defense mechanisms. In: Schrier RW, Gottschalk CW, eds. Diseases of the Kidney. In press.

2. Zimakoff J, Pontoppidan B, Larsen SO, Stickler DJ. Management of urinary bladder function in Danish hospitals, nursing homes and home care. J Hosp Infect 1993;24:183-199.

3. Zimakoff J, Stickler DJ, Pontoppidan B, Larsen SO. Bladder management and urinary tract infections in Danish hospitals, nursing homes, and home care: a national prevalence study. Infect Control Hosp Epidemiol 1996;17:215-221. 
4. Ouslander JG, Greengold BA, Silverblatt FJ, Garcia JP. An accurate method to obtain urine for culture in men with external catheters. Arch Intern Med 1987;147:286-288.

5. Nicolle LE, Harding GKM, Kennedy J, McIntyre M, Aoki F, Murray D. Urine specimen collection with external devices for diagnosis of bacteriuria in elderly incontinent men. J Clin Microbiol 1988;26:1115-1119.

6. Jarvis WR, Edwards JR, Culver DH, et al. Nosocomial infection rates in adult and pediatric intensive care units in the United States. Am J Med 1991;91(suppl 3B):185S-191S.
7. Haley RW, Gaynes RP, Aber RC, Bennett JV. Surveillance of nosocomial infections. In: Bennett JV, Brachman PS, eds. Hospital Infections. 3rd ed. Boston, MA: Little, Brown and Co; 1992:79-108.

8. Ouslander JG, Greengold B, Chen S. External catheter use and urinary tract infections among incontinent male nursing home patients. J Am Geriatr Soc 1987;35:1063-1070.

9. Ouslander JG, Greengold B, Chen S. Complications of chronic indwelling urinary catheters among male nursing home patients: a prospective study. J Urol 1987;138:1191-1195.

\section{Correction}

\section{Guideline for Isolation Precautions in Hospitals}

Due to a production error, an entry was positioned incorrectly in Appendix A of the "Guideline for
Isolation Precautions in Hospitals" (1996;17:53-80). The affected text, which appeared at the bottom of page
79 , is shown correctly below. We regret any inconvenience this may have caused our readers.

APPENDIX A (continued)

Type and Duration of Precautions Needed for Selected Infections and Conditions

\begin{tabular}{lc}
\hline \multicolumn{1}{c}{ Infection/Condition } & Precautions \\
\cline { 2 - 2 } Yersinia enterocolitica gastroenteritis (see gastroenteritis) & Type* $^{*}$ Duration \\
Zoster (varicella-zoster) & \\
Localized in immunocompromised patient, disseminated & $\mathrm{A}, \mathrm{C}$ \\
Localized in normal patient & $\mathrm{S}^{13}$ \\
Zygomycosis (phycomycosis, mucormycosis) & $\mathrm{S}$
\end{tabular}

